\title{
Evaluation of Spark Ignition Engine Performance Using Ethanol as Doping Agent on Constant Speed Test.
}

\author{
J.O Azubuike ${ }^{1 *}$, O.M.I Nwafor ${ }^{2}$, J.O Igbokwe ${ }^{3}$, D.O Isiohia ${ }^{4}$ \\ ${ }^{1,2,3}$. Mechanical Engineering Department, Federal University of Technology, P.M.B 1526, Owerri, \\ Imo State, Nigeria. \\ ${ }^{4}$ Mechanical Engineering Department, Imo State University, P.M.B 2000, Owerri, Imo State, \\ Nigeria.
}

${ }^{*}$ Corresponding author: azubuikejerry@gmail.com

\author{
Keywords: BSFC, Brake Power, Brake Thermal Efficiency, Fuel Flow Rate
}

\begin{abstract}
Engine knock is a critical phenomenon engine designers strive to minimize in the world today. Before now, this has made tetra ethyl lead (TEL) an option for minimizing knock. The basic essence of tetra ethyl lead is to enhance octane rating of petrol which is a vital factor to knocking ability. However, the health and environmental challenges associated with the use of tetra ethyl lead propel the desire to replace it with a better environmental and health friendly substance that will at the same time boost octane rating and give a smoother engine operation. Hence, ethanol was considered in this work at a constant speed test of $2000 \mathrm{rpm}$ and compared to leaded petrol as baseline petrol. BSFC of $0.703 \mathrm{~kg} \backslash \mathrm{kWhr}$ was obtained with $20 / 80$ compared to $0.709 \mathrm{~kg} \backslash \mathrm{kWhr}$ obtained with $0 / 100$ as baseline fuel. Maximum brake power of $0.74 \mathrm{~kW}$ occurred at a bmep of 1.235 bar with 15/85 ethanol/petrol. Similarly, maximum brake thermal efficiency of $13.44 \%$ was obtained with $20 / 80$ ethanol/petrol compared to $11.49 \%$ obtained with leaded petrol as baseline petrol. It is indicated that maximum power output, low BSFC and low petrol consumption was obtained with 20/80 ethanol/petrol blend. It is convincible that $20 / 80$ blend ratio offer good alternative to other antiknock agents which are associated with harmful consequences to man and environment. The implication of this work is that a definite blend for optimum performance and more environmentally friendly antiknock agent is established.
\end{abstract}

\section{Introduction}

The global issue of rapid reduction of petroleum fuels and their associated problems lead to extensive search for an alternative doping agent in place of the present doping agents. The key objective in this paper is to obtain a petrol/ethanol blend ratio that will give an optimum engine performance at constant speed condition. Thomas Midgeley Jr noticed the absence of unpleasant noise called engine knock when running on petrol doped with TEL. ${ }^{[5]}$ But unfortunately the risk associated with the use of the lead compound propelled the desire to seek for an alternative friendly antiknock doping agent in place of TEL. Hence it is a fruitless effort to obtain a solution to engineering challenges at the expense of environment and component suitability. According to USA Environmental Protection Agency, Lead exposure to human leads to gastrointestinal symptoms, brain and kidney damage, reproductive defects, cancers and so on. It further pointed out that early childhood and parental exposure causes slow cognitive development, learning plus other deficits ${ }^{[15]}$. Basically, engine knock is a resultant ofabnormal combustion taking place in cylinders of engines due to pressure oscillations which culminate to engine cycle efficiency deterioration, dramatic increase in exhaust emission, as well as metallic pinging noise. ${ }^{[6]}$ Usually the unburnt gases are compressed by the advancing flame front, which raises the temperature to a point of self-ignition and this result to an uncontrolled combustion, which is heard as engine knock sound. High engine knock could result to reduction of engine lifetime and damage of engine. More effects of engine knock are fracture of piston crown, cracks and rings grooves due to shock waves, melting of edges, high carbon deposits, piston seizure, low power output and efficiency. Oxygenates are among the effective ways of improving performance of any fuel ${ }^{[3]}$. Azubuike and Nwafor (2015) studied the performance of unleaded petrol 
doped with ethanol running on S.I engine at constant load condition and found out the critical reasons for advocating ethanol as an antiknock agent are due to its environmental friendly nature, availability, high fuel density, high octane value and low calorific value associated with ethanol. Minimum octane number requirement prevents engine knock and gives smooth engine operations. Ethanol was the first fuel among the alcohols to be used to power vehicles in the 1880s and 1890s [3] [9]. Henry Ford presented it as thefuel of choice for his automobiles during their earliest stage of development ${ }^{[3]}$. The engine performance with ethanol doped with petrol was seen to be better. However, the test condition was not specified. At low loads, engine performance with petrol doped with toluene was better than with pure petrol ${ }^{[11]}$. Mohd et al (2016) reported that performance characteristics showed that petrol doped with $20 \%$ ethanol performed better than pure petrol at all loads. It was revealed that use of ethanol completely and correct change of the spark timing could be a promising approach to enhance efficiency and environmental state of spark ignited engine ${ }^{[11]}$. It ispointed out that for $5 / 95$ blend from Salvinia molesta Bioethanol, there is no significant improvement in performance analysis compared to that using Petrol ${ }^{[12]}$. According to United State Department of Energy, Ethanol usually oxygenate the petrol more when it is blended with petrol thereby reducing air pollution. ${ }^{[16]}$ Chan-Wei et al (2004) in their engine test performance showed that $\mathrm{CO}$ and $\mathrm{HC}$ emissions were reduced as ethanol content in blend increases. ${ }^{[2]}$ It indicates an oxygen enrich fuel and affirm how environmental friendly petrol/ethanol blends are.

\section{Instrument and Experimental Procedures}

\subsection{Instrument}

At the cause of the experiment some material were used such as leaded petrol, unleaded petrol and ethanol blend, funnel and fuel hose and switch, tachometer, dynamometer, test tube, measuring cylinder, and reagents.

The unleaded petrol used was acquired from a refinery in Nigeria. The ethanol was extracted from woodchips (sawdust) from sawmill within Owerri Metropolis. The sawdust was subjected to saccharification process (Simultaneous Saccharification and Fermentation) to convert to glucose which ferments further to give out ethanol. These blends: 0/100, 5/95, 10/90, 15/85, 20/80, 30/70 and 40/60 (ethanol/petrol by volume) were characterized in line with America Standard for Testing and Material (ASTM) methods.

$\begin{array}{ll}\begin{array}{ll}\text { Engine Specifications } \\ \text { Bore }\end{array} & 68 \mathrm{~mm} \\ \text { Stroke } & 45 \mathrm{~mm} \\ \text { Compression Ratio } & 8.5 / 1 \\ \text { Fuel Tank Capacity } & 3.6 \text { litres } \\ \text { Number of Cylinder } & 1 \\ \text { Cooling Medium } & \text { Air } \\ \text { Engine Capacity } & 196 \mathrm{CC}\end{array}$

\subsection{Experimental Procedures}

A test rig was set up involving single compression ratio spark ignition engine. It was mounted with other auxiliary components needed for the experiment. The test was conducted at a constant engine speed of $2200 \mathrm{rev} / \mathrm{min}$ using different fuel blends. For each blend and load, fuel consumption rate, and torque were measured. Loads of values $9.81 \mathrm{~N}, 19.62 \mathrm{~N}, 29.43 \mathrm{~N}, 39.24 \mathrm{~N}$ and $49.05 \mathrm{~N}$ were considered. A schematic diagram of the engine test rig fuel flow system is shown and represented in figure 1. 
A digital tachometer was used to measures the speed, flow rates of petrol were capture from a glass tube and were used to compute brake power (bp) as shown in equation (1) below, brake thermal efficiency (bte) as shown in equation (4), brake specific fuel consumption (bsfc) as shown in equation (3) and brake mean effective pressure (bmep) as in equation (2). These computed data were obtained using the following relations.

$$
\begin{aligned}
& \mathrm{bp}=2 \pi \mathrm{NT} \\
& \left.\mathrm{bmep}=b p \times 60000 / A L N n \times 10^{\wedge} 5\right) \\
& \mathrm{bsfc}=\mathrm{M}_{\mathrm{f}} / \mathrm{bp} \\
& \mathrm{bte}=\mathrm{bp} / \text { energy supplied }
\end{aligned}
$$

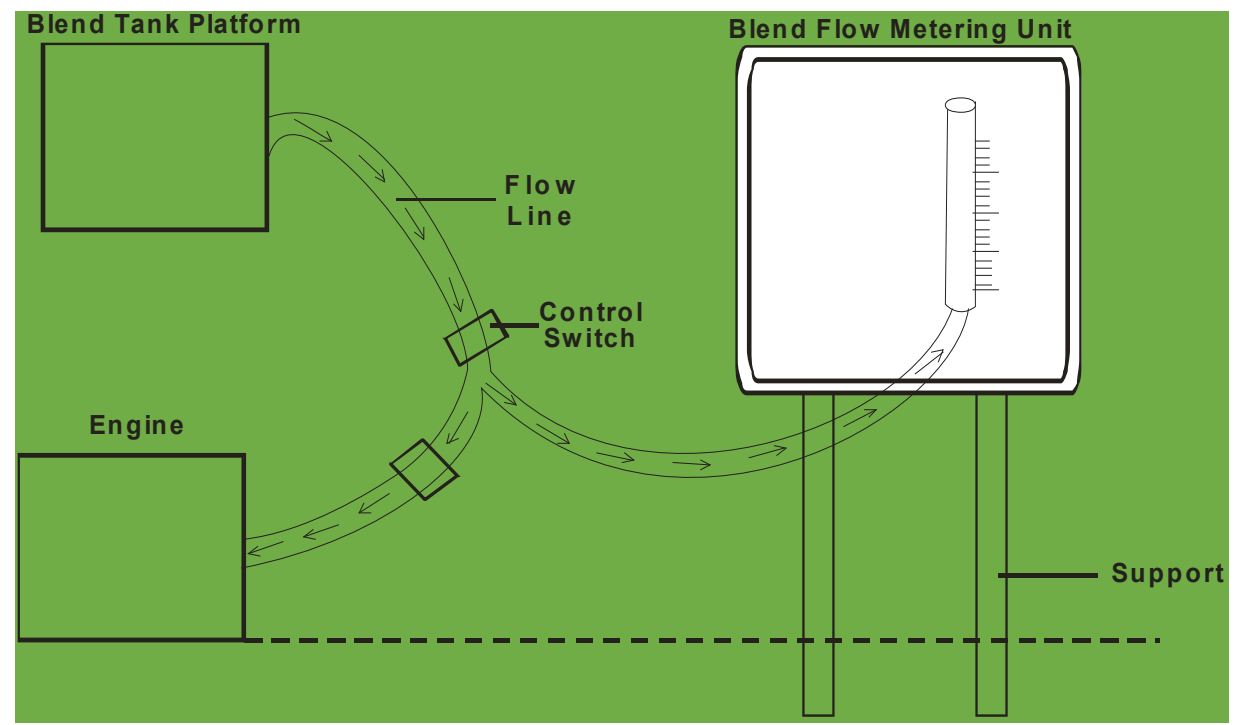

Figure 1. Engine Test Rig Fuel Flow System

Table 1. Characterization Result of Unleaded Petrol and Blends

\begin{tabular}{|c|c|c|c|c|}
\hline Sample & Density at $\mathbf{2 9}^{\circ} \mathbf{C}$ & Octane No. & Flash Point ${ }^{\circ} \mathbf{C}$ & $\begin{array}{c}\text { Calorific Value } \\
\text { (MJ/Kg) }\end{array}$ \\
\hline Unleaded Petrol & 746.70 & 93.20 & -65 & 44.30 \\
\hline $5 / 95$ & 747.10 & 95.10 & -54 & 43.80 \\
\hline $10 / 90$ & 748.20 & 97.20 & -40 & 41.80 \\
\hline $15 / 85$ & 752.00 & 98.60 & -36 & 41.20 \\
\hline $20 / 80$ & 761.30 & 100.40 & -20 & 38.10 \\
\hline $30 / 70$ & 775.60 & 102.70 & -15 & 37.70 \\
\hline $40 / 60$ & 780.20 & 106.30 & -13.5 & 37.40 \\
\hline
\end{tabular}

Source: Azubuike and Nwafor (2015)

Azubuike and Nwafor (2015) opined from their related work done on variable load conditions that increase in ethanol percentage in the blends at $29^{\circ} \mathrm{C}$ condition increased density of leaded petrol at 
$746.70 \mathrm{~kg} / \mathrm{m}^{3}$ to $780.20 \mathrm{~kg} \cdot \mathrm{m}^{3}$ for $40 / 60$ ethanol $/$ petrol by volume which represents about $4 \%$ increment. Octane number increases in same trend as ethanol/petrol percentage increases. This increase of octane number is known to improve the antiknock quality of the fuel. Calorific value shows the energytransferred as heat to the surrounding per unit quantity of fuel when burn at constant pressure and Table 1 shows a gradual decrease of calorific value as ethanol percentage increases. According to Kheiralla et al (2011), properties of the fuel from the result of test show that blend densities and kinematic viscosity increased continuously and linearly with increasing percentage of ethanol. Heat values was observed to decrease with increasing percentage of ethanol. ${ }^{[8]}$

\section{Results}

\subsection{Effect of Blends on BSFC at Constant Speed of $2200 \mathrm{rev} / \mathrm{min}$}

The graph on figure 2 below show the engine performance relationship of BSFC and BMEP of various blends in comparison with 100\% lead doped petrol.

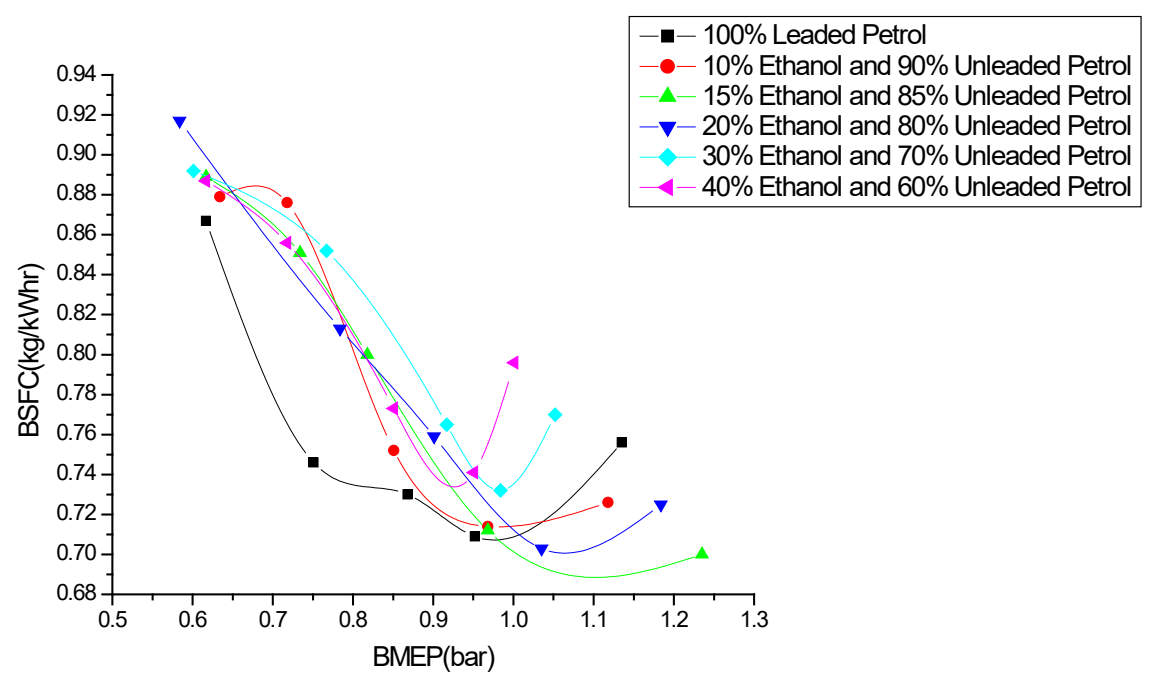

Figure 2. Graphs of BSFC against at BMEP at Constant Speed of $2200 \mathrm{rev} / \mathrm{min}$

The trends indicates that bsfc being dependent on fuel flow rate and brake power, decreases with bmep to a lowest point before increasing with increase in bmep. From the superimposed graphs figure 2, the lowest point of each blend indicates the best fuel economy when running at the same conditions. From figure 2, at constant speed test of $2200 \mathrm{rev} / \mathrm{min}$, the lowest bsfc of $0.703 \mathrm{~kg} / \mathrm{kWhr}$ occurred with 20/80 ethanol/petrol blend. When compared with other blends and the baseline petrol with a minimum bsfc of $0.709 \mathrm{~kg} / \mathrm{kWhr}$ at $2200 \mathrm{rev} / \mathrm{min}$. It gave an engine power with less fuel consumption. The superimposed graphs indicate that lower bsfc was obtained as the percentage of ethanol increases in the blends. At the lowest bsfc value on the graphs, it means that enough air was available for complete combustion. This is due to oxygen atom contained in chemical formula of ethanol $\left(\mathrm{CH}_{3} \mathrm{CH}_{2} \mathrm{OH}\right)$, which aid combustion. Khan and Nath (2007) found out from experiment that of S.I engines running on blend ratio $15 \%$ ethanol and $85 \%$ petrol had a slight lower BSFC than $100 \%$ petrol and it has further validate the above result presented. ${ }^{[10]}$

\subsection{Effect of Blends on Brake Power at Constant Speed of $2200 \mathrm{rev} / \mathrm{min}$}

Figure 3 below show the engine performance relationship of BP and BMEP of various blends in comparison with $100 \%$ lead doped petrol. 


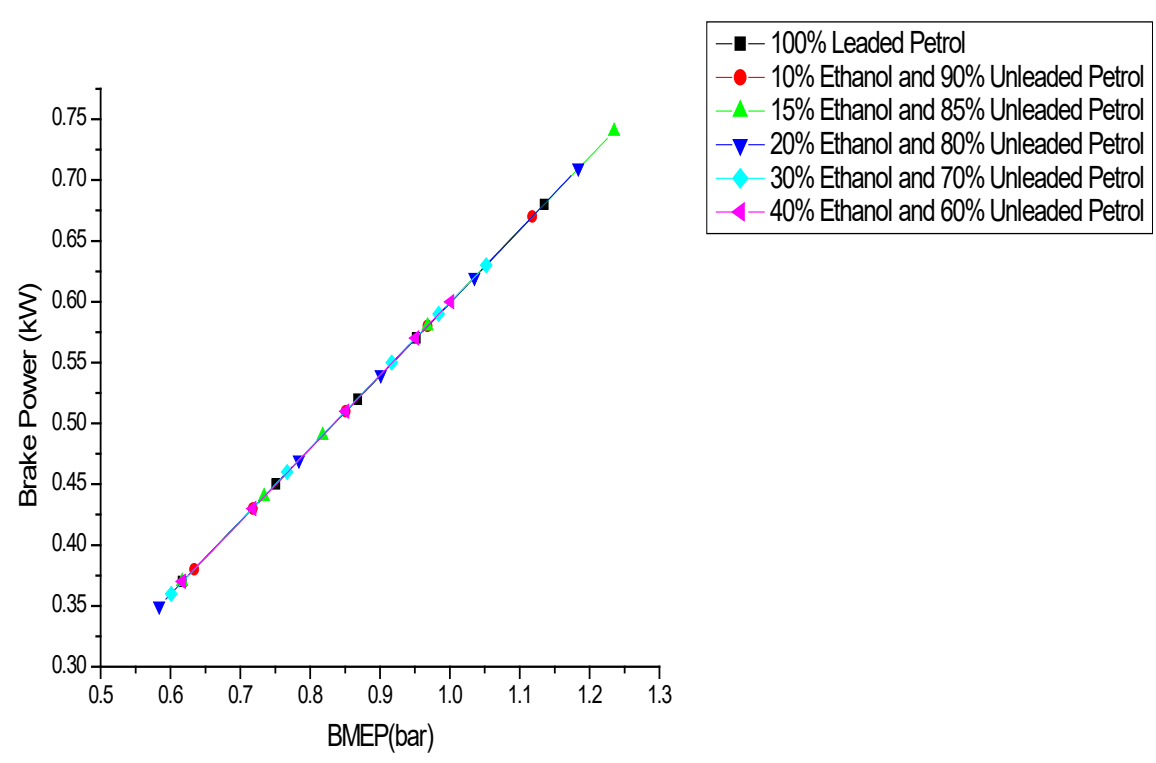

Figure 3. Graphs of Brake Power against BMEP at Constant Speed Test of $2200 \mathrm{rev} / \mathrm{min}$

Figure 3 shows a maximum brake power of $0.74 \mathrm{~kW}$ occurring at a bmep of 1.235 bar with blend of $15 / 85 \mathrm{ethanol} / \mathrm{petrol}$ at a constant speed of $2200 \mathrm{rev} / \mathrm{min}$. This decrease in brake power developed at $2200 \mathrm{rev} / \mathrm{min}$ suggests that brake power depend on engine speed and torque. This indicates that the breathing capacity (volumetric efficiency) of spark ignition engines declines beyond certain engine speed as torque drops.

\subsection{Effect of Blends on Brake Thermal Efficiency at Constant Speed of $2200 \mathrm{rev} / \mathrm{min}$}

Figure 4 indicates the relationship of bte and bmep at a constant speed.

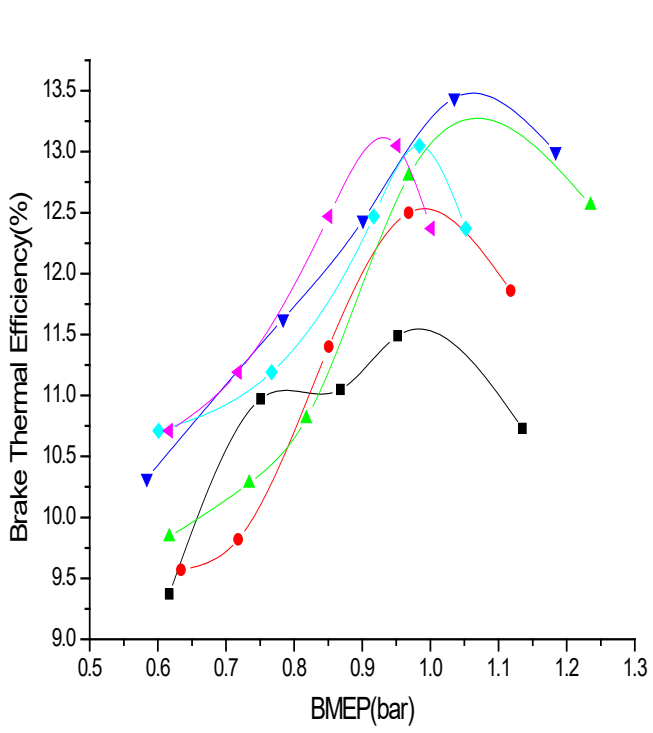

- $100 \%$ Leaded Petrol

- 10\% Ethanol and 90\% Unleaded Petrol

$-15 \%$ Ethanol and $85 \%$ Unleaded Petrol

- $-20 \%$ Ethanol and $80 \%$ Unleaded Petrol

$-30 \%$ Ethanol and $70 \%$ Unleaded Petrol

$4-40 \%$ Ethanol and $60 \%$ Unleaded Petrol

Figure 4. Graphs of Brake Thermal Efficiency against BMEP Constant Speed of $2200 \mathrm{rev} / \mathrm{min}$

Brake Thermal Efficiency is the ratio of brake power to heat energy supplied and it indicates the ability of an engine to convert petrol energy into useful power output. Figure 4 above shows that brake thermal efficiency (bte) increases with rising bmep. With constant speed test of $2200 \mathrm{rev} / \mathrm{min}$, the maximum brake thermal efficiency occurred with $20 / 80$ ethanol/petrol with a value $13.44 \%$ and $11.49 \%$ with $100 \%$ leaded petrol. The increase is due to decrease of calorific value of $20 / 80$ blend. 


\subsection{Effect of Blends on Fuel Flow Rate at Constant Speed of $2200 \mathrm{rev} / \mathrm{min}$}

The graph in figure 5 below show the relationship of flow rate with BMEP at a constant speed.
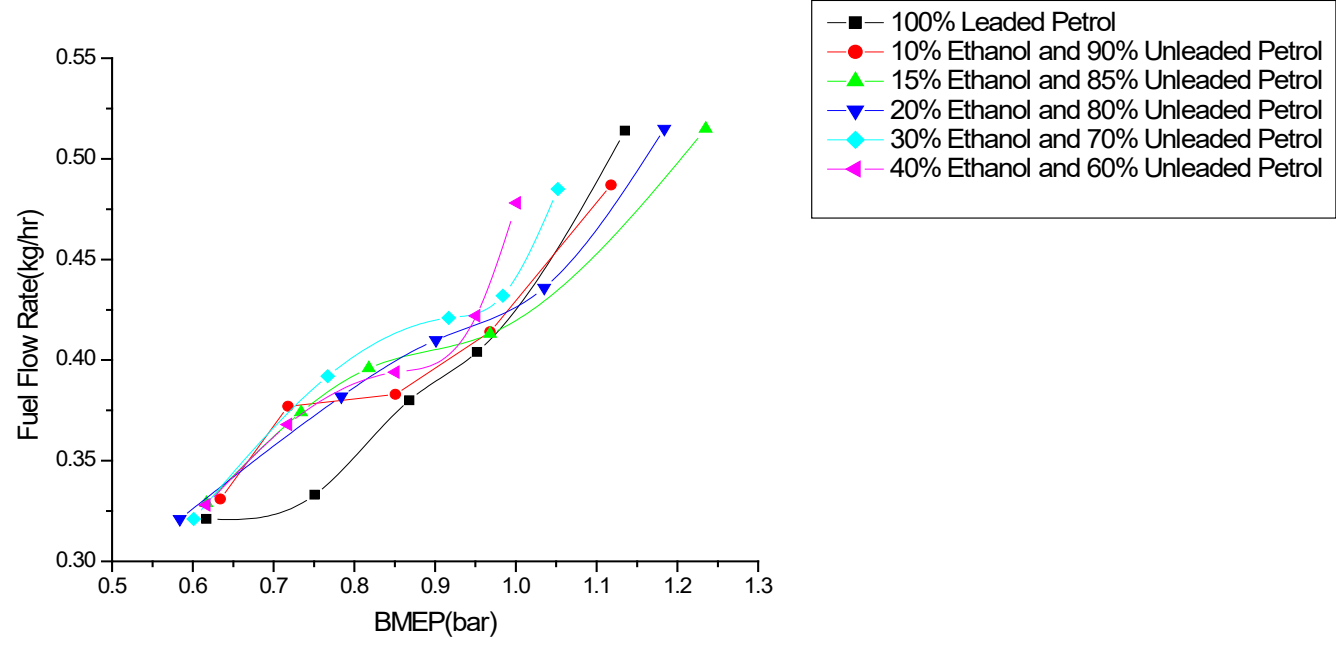

Figure 5. Graphs of Fuel Flow Rate against BMEP at Constant Speed of 2200

Figure 5 shows that bmep acting on the piston increases as the fuel flow rate increases. The lowest fuel consumption of $0.321 \mathrm{~kg} / \mathrm{hr}$ was obtained when running on blend 20/80 at a speed of 2200 $\mathrm{rev} / \mathrm{min}$. Fuel consumption increases with increase in bmep so as to sustain the power requirement of the engine.

\section{Conclusion}

The results obtained on constant speed test at $2000 \mathrm{rpm}$ when running on petrol doped with ethanol indicated that maximum brake power output, low BSFC and low fuel consumption were obtained with 20/80 ethanol/petrol blend. They show that 20/80 ethanol/petrol blend by volume can offer good alternative antiknock fuel devoid of TEL as antiknock agent. It raises confidence that with ethanol blend in petrol as antiknock, our environment and health can be sustained with better engine performance.

\section{Conflict of Interest Statement}

The research results presented in this paper is the original work of the Authors. The Authors declares that there is no conflict of interest of any kind.

\section{References}

[1] A.C Alkidas (2007) Combustion Advancement in Petrol Engines. Energy Conversion and Management (48) 2751-2761.

[2] Chan-Wei Wu, Rong-Hong Chen, Jen-Yung Pu, Ta-Hui Lin (2004) The Influence of air-fuel ratio on Engines performance and Pollutants emission of an S.I Engine using Ethanol-gasoline blended fuels. Journal of Atmospheric Environment Volume 38 Issue 40 pp 7093-7100.

[3] D. Houghton-Alico (1982) Alcohol fuels production and potential, Colorado.

[4] D. Piernikarski, J. Hunicz, and H.Komasta (2013) Detection of knocking Combustion in a spark Ignition Engine using optical signal from the combustion chamber 15(3):214-220.

[5] GM Engineers Discover that lead Gas Reduce (2014), the history channel website retrived 24 September $2012 \mathrm{hptt} / \mathrm{www}$.history.com 
[6] J.B Heywood, Internal Combustion Engine Fundamental McGraw-Hill New York.

[7] J.O Azubuike and O.M.I Nwafor (2015) "Performance Evaluation of Spark Ignition Engine at Constant load using ethanol as doping agent" American Journal of Mechanical Engineering, Volume 3 No 4 122-125 doi 10.12691/ajme-3-4-3.

[8] Kheiralla Abdelmotalab, El-Awad Mohamed, Hassan Mathani, Hassan M and Osman Hind (2011) Effect of Ethanol/Gasoline blends on Fuel properties Characteristics of Spark Ignition Engines. University of Khartoum Engineering Journal Volume 1 pp 22-28.

[9] M.Alhasan (2003) Effect of Ethanol-Unleaded Petrol blends on engine performance and exhaust emission. Energy conversion and management (44) 1547-1561.

[10] M.Y Khan and S Nath (2007) Performance Characteristics of Spark Ignition Engine when operated on blends of ethanol and petrol. Proc of all India Seminar on Mechanized World and Scarcity of Fuel, Brahmpur.

[11] Mohd Yunus khan, Praveen Pachaun and Atishey Mittal (2016) Performance Evaluation of Spark Ignition Engine Running on Petrol doped with various additives. International Journal of Advance Research in Science and Engineering Volume 5 Issue 08 Pp 465-472.

[12] Priyank Gupta, Partha Protim Das, M Mubarak and A Shaija (2018) Performance and Emission Analysis of Single Cylinder Spark Ignition Engine using Bioethanol-gasoline blend produced from Salvina Molesta. International Conference on Mechanical Engineering.

[13] R.K Rajput (2008) “A textbook of Internal Combustion Engines" $2^{\text {nd }}$

[14] Edition, Laxmi Publications Ltd, 113 Golden House Daryaganj New Delhi.

[15] R.G Papagiannakis, D.C Rakopoulos and C.D Rakopoulos (2017) Theoritical Study of the Effects of Spark Timing on the Performance and Emissions of a Light duty Spark Ignited Engine running under either Gasoline or Ethanol or Butanol Fuel operating modes. Energies Journal (10), 1198.

[16] USA Environmental Protection Agency (2011) Air Quality Criteria for Lead. EPA's Integrated Risk Information System. www.epa.gov accessed on 13/01/2020.

[17] www.afdc.energy.gov - Energy Efficiency and Renewable Energy. Accessed on 12-08-2020. 